\title{
Growth Cone Morphology Varies with Position in the Developing Mouse Visual Pathway from Retina to First Targets
}

\author{
Paola Bovolenta ${ }^{a}$ and Carol Mason \\ Department of Pharmacology, New York University School of Medicine, New York, New York 10016
}

We have labeled the growth cones of retinal ganglion cell axons with HRP in intact mouse embryos. This has allowed us (1) to visualize growth cone morphology during outgrowth along an entire CNS pathway from origin to target; (2) to ask whether growth cone forms, and thus behaviors, differ at various points along the pathway; and (3) to study the relationships of growth cones with the cellular environment.

During the major period of axon outgrowth between embryonic day (E) 12 and 15, growth cones in the optic nerve are highly elongated (up to $40 \mu \mathrm{m}$ ) and have lamellopodial expansions, but the majority lack the microspikes or filopodia characteristic of many growth cones. Within the optic chiasm (E13-15), most growth cones shorten and spread, and project several short filpodia. In the optic tract, growth cones become more slender and again lack filopodia, resembling sleeker versions of optic nerve growth cones. Near the first target region (lateral geniculate nucleus), growth cones with filopodia arise from individual axon lengths and turn medially toward the target. Within target regions, the branches of immature axon arbors are tipped by minute swellings rather than by the enlarged growth cones prevalent during outgrowth toward targets.

Electron-microscopic analysis of identified labeled growth cones in the optic nerve reveal intimate interactions between growth cones and glia or other growth cones in the form of invaginating contacts. In the optic nerve, growth cones contact immature glial (neuroepithelial) cells somewhere along their length, and also envelop bundles of neurites. In the chiasm, single growth cones simultaneously relate to many different profiles.

These results demonstrate that in this single pathway from origin to targets, growth cone morphology varies systematically with position along the visual pathway. During outgrowth, simple growth cones are prominent when axons fol-

\footnotetext{
Received May 23, 1986; revised Nov. 3, 1986; accepted Dec. 3, 1986.

This work was supported by NIH Grant NS-16951 and a Research Career Development award to C. M., who also holds an Irma T. Hirschl Career Scientist Award. Elizabeth Gregory and Kristy Brown gave expert assistance in electron microscopy, Susan Catalano helped with illustration, and Yvel Calderon and Julia Cohen typed the manuscript. We are grateful to Drs. Lloyd Greene and Mary Beth Hatten for their useful comments on the manuscript, and Drs. John Aletta, Paul Letourneau, Norm Wessells, and Rob Williams for their insightful discussions.

Correspondence should be addressed to Carol Mason, Department of Pharmacology, New York University Medical Center, 550 First Avenue, New York, NY 10016.

a Present address: Department of Physiology and Cellular Biophysics, Columbia University, College of Physicians and Surgeons, 630 West 168th Street, New York, NY 10032.

Copyright (C) 1987 Society for Neuroscience $0270-6474 / 87 / 051447-14 \$ 02.00 / 0$
}

low well-defined common pathways, and more elaborate filopodial forms appear when growth cones diverge, as they turn or come to decision regions. Together with observations in vitro and in nonmammalian nervous systems in situ, these data serve as reference points for testing to what extent growth cone form reflects intrinsic factors and interactions with the environment.

As the growing end of a developing axon, the growth cone guides the axon, chooses among different substrates, leads the way into target regions, and ultimately synapses with certain target neurons (Rees et al., 1976; Johnston and Wessells, 1980; Letourneau, 1982; Landis, 1983). Recent evidence from observations of ncurons in vitro, in invertebrates, and in the PNS of lower vertebrates in situ, suggests that the shape of growth cones correlates with their behavior (Raper et al., 1983; Argiro et al., 1984; Tosney and Landmesser, 1985a). One hypothesis derived from this recent work is that growth cone shapes transform during navigation along pathways, as a response to environmental cues for neurite extension and directionality (Caudy and Bentley, 1986a).

There is some reason to think that growth cones in the CNS, especially in mammalian nervous systems, might not obey the same rules. For example, it is unclear whether populations of neurons have a single leading or "pioneer" neuron (Keshishian, 1980), which during some developmental stages has a more complex shape than the follower axons (Lopresti et al., 1973). Indeed, axon populations in CNS pathways are orders of magnitude larger, perhaps obviating the need for axon "scouts."

In this study, we were able to visualize growth cones during the outgrowth phase, in a major CNS pathway in mammalian brain. We labeled retinal ganglion cell axons by injecting IIRP into the retina of isolated but intact mouse embryos. This approach has produced novel views of populations of growth cones along the entire visual pathway from retina to first targets in the thalamus and allowed us to observe whether the form of retinal axon growth cones is invariant along a pathway or changes as growth cones travel through different environments where they display different behaviors. Axons grow relatively straight in the tubular pathways of optic nerve and tract, but in the optic chiasm the majority cross over to the contralateral optic tract. A turn is also required when axons enter thalamic targets medial to the tract.

A second question is whether growth cone forms are different during outgrowth, when axons must extend over great distances, as compared to synaptogenesis within target regions, where selection of target cells is made over shorter distances. Previous studies have characterized the form and cell-cell relations of 
growth cones within targets of retinal axons in the kitten lateral geniculate nucleus and in the mouse cerebellum, during preand postnatal development of axon arbors and synaptogenesis (Mason and Robson, 1979; Mason and Gregory, 1984; Mason, 1985; Sretavan and Shatz, 1986). The tips of maturing axons during this phase lack the typical forms of growth cones seen during outgrowth in vitro, stereotypically, flattened flanks with long filopodia (Bray and Bunge, 1973; Letourneau, 1979). Instead, most are minute tapered forms that lack microspikes, especially on axons that develop highly branched arbors.

Another issue is how growth cones interact with the surrounding cellular and extracellular environment in each portion of a varied pathway during outgrowth and synaptogenesis. Because we have labeled individual growth cones with electron-dense HRP, we can begin to address this question and readily determine how identified growth cones relate morphologically to surrounding cells. The types of cell-cell relationships during the different outgrowth behaviors have not been well characterized in the systems in which growth cones have been studied.

The results of the present study show, first, that growth cone morphologies change in different portions of the pathway from retina to target, and, second, that growth cones interact with both contiguous neurons and glia, even when exploration is not part of a particular behavior.

\section{Materials and Methods}

In order to visualize growing axons in the mouse visual system, axons were labeled with HRP, following a slight modification of a previously described technique (Mason and Gregory, 1984; Mason, 1985).

$H R P$ injections and tissue preparation. All experiments were carried out with C57B1/6J mice derived from a timed-pregnancy breeding colony in this department. Pregnant mothers were anesthetized with Nembutal, and embryos removed one at a time by cesarean section. Embryos were decapitated, and the whole heads or dissected brains were placed in a Petri dish filled with tissue culture medium consisting of Eagles basal medium with Hank's salts, glucose ( $8 \mathrm{~mm})$, glutamine ( $4 \mathrm{~mm})$, and penicillin/streptomycin $(20 \mathrm{ml} / \mathrm{ml})$. The preparations were illuminated from below and kept at $37^{\circ} \mathrm{C}$ by means of an air curtain incubator (Arenberg Sage). Glass micropipettes with a 10-30 $\mu \mathrm{m}$ tip were coated with a concentrated solution of HRP (Sigma, type IV) and allowed to dry. In order to label axons and their growth cones in the nerve and chiasm, HRP-coated glass micropipette tips were inserted into the retina between embryonic day (E) 12 and E16 (E0 being the plug day). Axons and growth cones in the optic tract and target regions were visualized by injections into the chiasm of freshly dissected brains.

After a resting period of $30 \mathrm{~min}$ to $2 \mathrm{hr}$, the heads or brains were fixed by immersion in $3 \%$ glutaraldehyde in $0.1 \mathrm{M}$ phosphate buffer, $\mathrm{pH}$ 7.3. The tissue was stored in fixative overnight at $4^{\circ} \mathrm{C}$ and then embedded in gelatin albumin hardened with glutaraldehyde. Horizontal sections were cut at $50 \mu \mathrm{m}$ on a vibratome (Oxford) and placed in phosphate buffer. The sections were reacted in diaminobenzidine (Sigma) in phosphate buffer and hydrogen peroxide, with cobalt-nickel enhancement (Adams, 1981) if used only for light microscopy or without cobalt treatment if prepared for electron microscopy. Sections for light microscopy were washed in buffer, mounted on gel-coated slides, dehydrated, cleared in xylene, and mounted with Permount (Fisher). Sections prepared for electron microscopy were rinsed in buffer, osmicated, and stained en $b l o c$ with uranyl magnesium acetate; they were then dehydrated in ethanols, embedded in Epox (Fullam) between 2 plastic slides, and allowed to polymerize at $60^{\circ} \mathrm{C}$ for $1-2 \mathrm{~d}$.

Correlative light and electron microscopy. The correlative light- and electron-microscopic analysis was carried out as previously described (Mason and Gregory, 1984). The thin plastic wafer was separated from the plastic slides and placed on a glass slide. Labeled axons and growth cones were examined in the light microscope and drawn with the aid of a Leitz drawing tube and $100 \times$ oil-immersion objective. Selected pieces of the wafer were glued to Epon stubs and sectioned with a glass knife at $7 \mu \mathrm{m}$. The sections were placed on glass slide, and those containing pieces of the original axons were drawn at the same magnifi- cation, as well as photographed with phase-contrast optics. By placing the drawing of the $7 \mu \mathrm{m}$ sections on the original drawing, pieces of the axons and growth cones of interest became evident. The selected $7 \mu \mathrm{m}$ sections were removed from slides and remounted onto faced-off block. Thin sections were cut and placed on single-holed Formvar-coated grids, stained with uranyl acetate and lead citrate and examined on a JEOL $100 \mathrm{~S}$ EM. The drawings of the 50 and $7 \mu \mathrm{m}$ sections, as well as the phase photographs, served as guides for relocating specific axons and growth cones. Over 170 preparations between E12 and E19 were examined at the light microscope; of these, 15 were also analyzed with the EM.

Definitions and quantitation of growth cone features. Over 300 growth cones were drawn with a camera lucida at $1000 \times$ magnification. Growth cones were defined as the expansion of the distalmost constriction of the neurite. In many cases, growth cones appeared to consist of a series of expansions. If a thin segment of neurite was absent between these expansions, the series was considered to be a single growth cone.

There were 2 types of structures arising from the core or flanks of the body of the growth cone: (1) filopodia, thin $(<0.5 \mu \mathrm{m})$ projections that were uniform in diameter from base to tip and ranged in length from 1 to $15 \mu \mathrm{m}$, and (2) lamellopodia, thin veil-like extensions of the central core of a growth cone, curved in either a convex or concave manner. Filopodia were rarely branched but occasionally divided once without a change in diameter. Some (e.g., Bray and Chapman, 1985) have termed filopodia microspikes; others might refer to the shorter filopodia $(<3$ $\mu \mathrm{m})$ as microspikes, when compared to the very long $(50 \mu \mathrm{m})$ filopodia of insect growth cones. We have used the term filopodia for these structures regardless of length. Lamellopodia never extended from the central core of the growth cone further than $8 \mu \mathrm{m}$. Growth cones were considered "filopodial" if they had one or more filopodia and "lamellopodial" if they consisted of one or more velate extensions and lacked filopodia. If neither of these categories applied, the specific features were described in the text.

Measurements of growth cone dimensions and filopodia number and length were made from the camera lucida tracings. The maximum width and maximum length from neurite to end of the growth cone flank were measured, in both cases excluding filopodia. The average number of filopodia and their average length were computed only for those growth cones with filopodia. Branched filopodia were counted as one.

\section{Results}

Retinal ganglion cells in the mouse begin to extend their axons at E11. Injections of HRP in E11 retina stained only retinal ganglion cell bodies, but at E12, it was possible to label a few retinal ganglion axons. These extended out of the eye cup and grew along the side of the optic stalk, away from pigment. The majority of growing axons in the optic nerve were labeled between E13 and E14, and at this age, growing fibers also invaded the pigmented part of the stalk. At E15, labeled growth cones were scarce in the optic nerve, and by E16, the HRP labeling technique failed to reveal the presence of any growth cones within the nerve. Growth cones were labeled in the chiasm primarily between E13 and E15, and fibers were labeled in the optic tract between E14 and E18.

\section{Position of growth cones within the visual pathway}

Growth cones were found both along the outer edge and the inner portion of the optic nerve. Axons arising from the ventrotemporal retina ran in the dorsal half of the optic nerve and turned into the ipsilateral optic tract. The majority of optic fibcrs were located in the ventral part of the nerve and, as they entered the optic chiasm, turned toward the contralateral side. Labeled fibers tipped by growth cones ran primarily in the anterior borders of the chiasm at the pial edge (Fig. 4), as if later fibers were always added at the pial surface.

Once in the optic tract, growth cones tended to follow the outer surface of the tract. When fibers in the tract gave rise to branches that project to target regions, such as the lateral ge- 

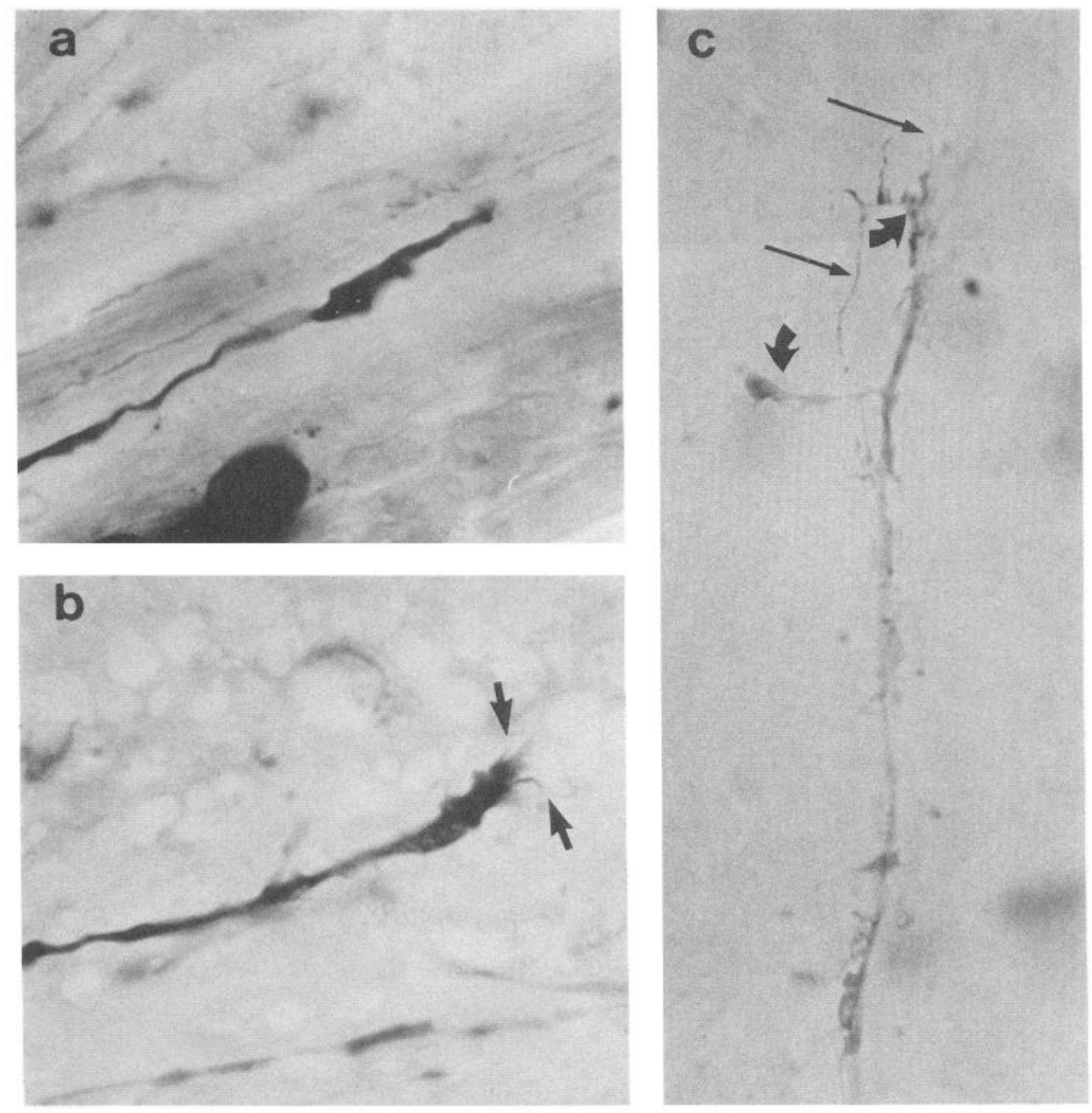

Figure 1. Typical growth cone morphologies in the various regions of the retinal axon pathway at E13 $(a, b)$ and E15 (c). Photomicrographs were taken from osmicated $50 \mu \mathrm{m}$ vibratome sections. $a$, Growth cones in the optic nerve are long and narrow, with concave and convex lamellopodial expansions of the central core. $b$, Growth cones in the chiasm have shorter flanks and bear multiple filopodia (arrows). c, Fibers in the optic tract at the level of target regions have growth cone-like expansions that point medially (curved arrow) toward the target lateral geniculate nucleus. Filopodia arise from these growth cones and extend both toward the target and into the tract (straight arrows). $\times 1070(a-c)$. niculate nucleus (LGN), both the main shaft of the axon and the branches were positioned in the more medial regions of the tract. In all portions of the pathway, fibers did not run straight but interwove to a considerable extent (Fig. 4).

\section{Growth cone morphology}

Growth cones had a broad spectrum of morphologies along the pathway from the eye to the target, but their shape could be grossly characterized by the region of the pathway through which they traversed (Fig. 1).

Optic nerve. The silhouettes of optic nerve growth cones at various ages are illustrated with camera lucida drawings (Fig. 2). At E12 the growing tips of the few fibers labeled in the optic stalk were simple, without many surface features or projections, but relatively long (up to $20 \mu \mathrm{m}$ ). From E13 and E15, growth cones in the nerve had similar characteristics. Many optic nerve growth cones had a central core with lamellopodial extensions (asterisks in Fig. 2). Most growth cones were rather long, with an average length of $23 \mu \mathrm{m}$, but some reached $40 \mu \mathrm{m}$ (Fig. $1 a$ and Fig. 2). The most complex optic nerve growth cones consisted of a series of concave and convex lamellopodial expansions (arrowheads in Fig. 2). The majority of growth cones within the optic nerve lacked filopodia (Figs. $1 a$ and 2; Table 1). By E15 the few growth cones that were visualized by HRP labeling were shorter and still had lamellopodial extensions, but a larger proportion bore short filopodia (Fig. 2, Table 1). Thus, the growth cones in the optic nerve differed strikingly from the stereotypic growth cones in vitro, which have spread forms with extensive filopodia (Bray and Bunge, 1973).

Variation in growth cone shapes appeared to be loosely related to the age of the embryo. The earliest growing axons had more compact growth cones, while the "followers," in the major phase of outgrowth at E13-14, more commonly displayed lamellopodial expansions.

Optic chiasm. Growth cone morphologies were strikingly different in the optic nerve and in the optic chiasm. The most obvious change within the chiasm was the presence of several filopodia, 3-10 $\mu \mathrm{m}$ in length, arising from the main body of the growth cone (Figs. 1b, 3 (closed arrowheads), and 4; Table 1). An additional change was a reduction in length and slight broadening of the main body of the growth cone (Figs. 3, 4). At E13 the average length of growth cones was $14 \mu \mathrm{m}$, as compared to $23 \mu \mathrm{m}$ for optic nerve growth cones of the same age (Table 1). Growth cones in the chiasm generally had more complex 3-dimensional surface features than those in the optic nerve (Fig. 3, asterisks). The only age-related feature was a slight shortening of growth cone length by E15 (Table 1).

Most growth cones within the chiasm had filopodia and the majority of growth cones in optic nerve lacked filopodia, but this feature was not the sole criterion for distinguishing them 
E12
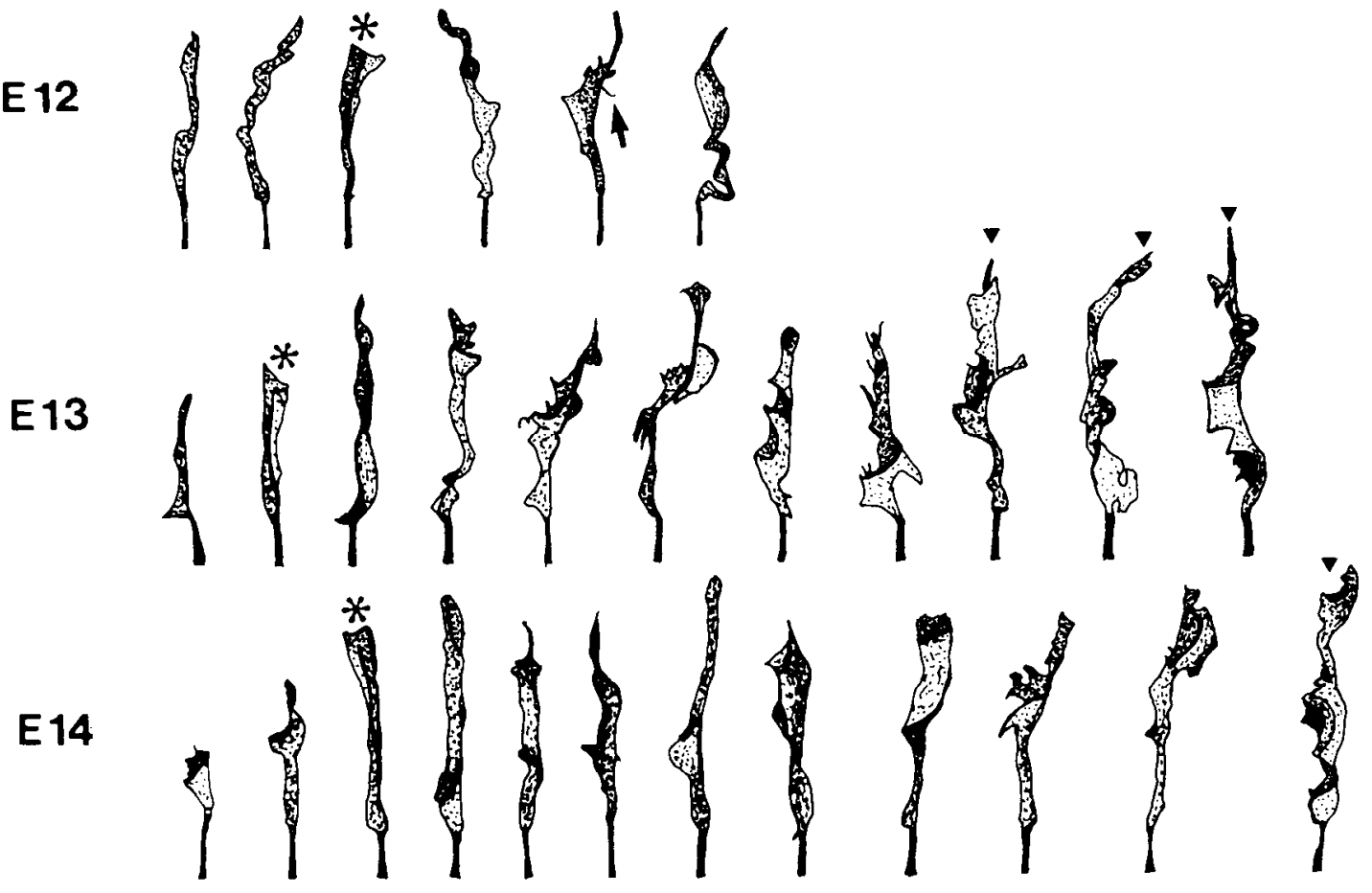

E 15

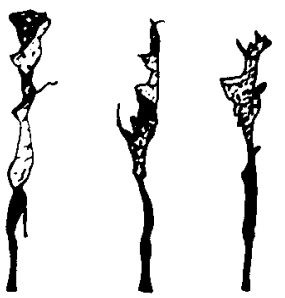

\section{OPTIC NERVE}

Figure 2. Camera lucida drawings of HRP-filled growth cones in the optic nerve during the major pcriod of outgrowth. $\Lambda$ s in Figures 3 and 5 , the actual growth cone is considered to be the stippled expansion of the neurite, which is indicated in black. At E12 growth cones have more smooth surfaces than at later ages. Many of the growth cones from E13-15 are highly elongated with a series of thin convex and concave lamellopodial expansions (arrowheads). In some growth cones, a central core is visible (asterisks). Filopodia are only occasionally seen and rarely exceed 2 in number (arrow). Scale bar, $10 \mu \mathrm{m}$.

(Figs. 3 (open arrowheads), and 4; Table 1). Growth cones in the nerve were always much longer than they were wide, and if they bore filopodia, never had more than 2 (Fig. 2, arrow; Table 1). In the chiasm, the growth cones that lacked filopodia, more closely resembled optic nerve growth cones, e.g., elongated lamellopodial forms (Fig. 3, open arrowheads, and Fig. 4, growth cones 3 and 4). Filopodia on growth cones in the nerve or chiasm were of similar length, but growth cones in the chiasm had, on the average, at least 2 more filopodia than did growth cones in the nerve.

An unusual feature of growing axons in both optic nerve and chiasm was noted. In addition to the leading growth cone at the end of the axon, velate or irregular expansions occurred en passant along the axon (Fig. 4, arrows on growth cones 2 and 5). By their shape, these expansions were interpreted as remnants of growth cones rather than swellings that arose after extension.

Optic tract. In order to label growth cones in the optic tract, HRP-coated glass micropipettes were inserted directly into the embryonic chiasm in isolated brains. Midway between the optic chiasm and LGN, growth cones were commonly located on fibers that ran on the outer surface of the optic tract (Fig. 5a) and their shapes did not seem to vary with age. Growth cones on fibers in the optic tract were more slender versions of optic nerve growth cones (Fig. 5a, Table 1). They were relatively compact with tapered tips and were much shorter than optic nerve growth cones, with an average length of $9 \mu \mathrm{m}$. Some tract growth cones had filopodia or small spines along their length (Fig. $5 a$ ). A greater proportion of growth cones had filopodia at later ages (Table 1).

When fibers reached the border of target regions such as the LGN, a further transformation occurred. Axons positioned more deeply in the tract gave rise to long smooth expansions that bore several filopodia (Figs. $1 c$ and $5 b$, arrows). Some of these expansions were en passant but were always oriented medially toward the target. Filopodia on these growth cones tended to be more numerous and longer than growth cones in the chiasm $(10-15 \mu \mathrm{m})$ and were oriented in all directions. Short filopodia 
E 13
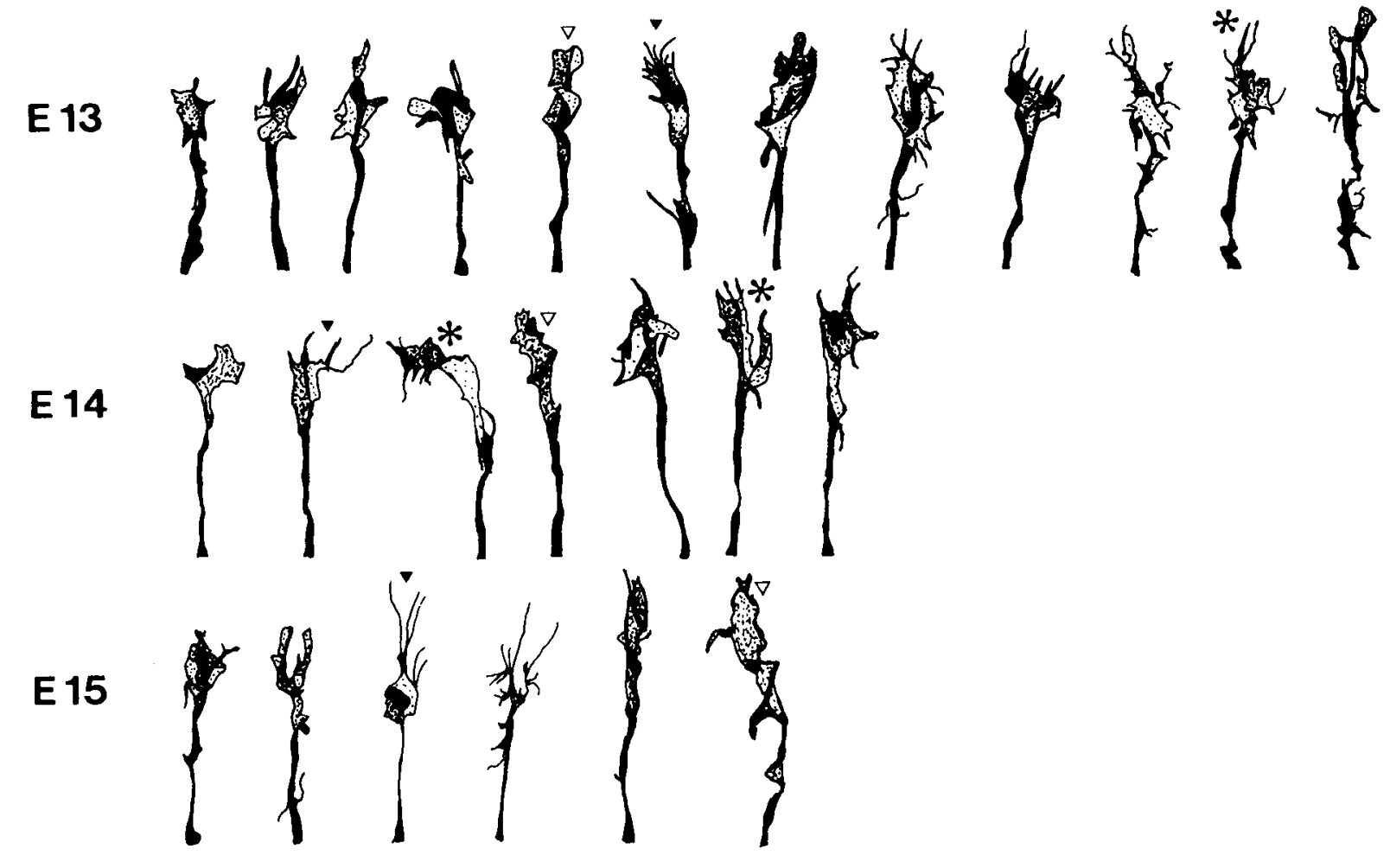

\section{OPTIC CHIASM}

Figure 3. Camera lucida drawings of growth cones in the optic chiasm at the ages when growth cones are common in this region. Growth cones are shorter and wider than those in the optic nerve and have more complex 3-dimensional morphology (asterisks) with multiple filopodia (filled arrowheads). Some chiasm growth cones lack filopodia (open arrowheads) and resemble optic nerve growth cones, both in length and shape. As in the optic nerve, few age-related effects on morphology are evident (see Table 1). Scale bar, $10 \mu \mathrm{m}$.

also arose along the length of these neurites.

Targets. Once axons entered targets, dramatic changes took place in growth cone size and form. Rather than having the large growth cones seen on unbranched neurites, the branched arbors were tipped in small swellings $<1 \mu \mathrm{m}$ in diameter that were barely visible at the light-microscopic level. These minute swellings occurred on axons that projected to proper targets such as the LGN (Fig. 6b), as well as on axons that projected to inappropriate regions (Fig. $6 a$ ). Some of the axons that were labeled with HRP projected to nonvisual "inappropriate" targets. Fibers

Table 1. Position-related features of growth cones at different ages

\begin{tabular}{lllllll} 
Tissue & $n$ & $\begin{array}{l}\text { Maximum } \\
\text { length } \\
(\mu \mathrm{m})\end{array}$ & $\begin{array}{l}\text { Maximum } \\
\text { width } \\
(\mu \mathrm{m})\end{array}$ & $\begin{array}{l}\text { Percentage } \\
\text { with } \\
\text { filopodia }\end{array}$ & $\begin{array}{l}\text { Number of } \\
\text { filopodia }\end{array}$ & $\begin{array}{l}\text { Length of } \\
\text { filopodia } \\
(\mu \mathrm{m})\end{array}$ \\
\hline $\begin{array}{llllll}\text { Optic nerve } \\
\text { E13 }\end{array}$ & 30 & $23.2 \pm 6.8$ & $4.5 \pm 1.2$ & 30 & $1.5 \pm 0.7$ & $3.4 \pm 1.6$ \\
E14 & 31 & $23.3 \pm 7.7$ & $3.7 \pm 1.7$ & 22 & $1.0 \pm 0.0$ & $3.6 \pm 1.4$ \\
E15 & 17 & $15.7 \pm 7.7$ & $2.9 \pm 1.1$ & 41 & $1.4 \pm 0.5$ & $3.1 \pm 1.8$ \\
Optic chiasm & & & & & & \\
E13 & 35 & $15.1 \pm 2.8$ & $6.7 \pm 2.0$ & 71 & $2.4 \pm 1.4$ & $3.8 \pm 1.7$ \\
E14 & 20 & $15.5 \pm 4.1$ & $6.4 \pm 2.3$ & 70 & $2.4 \pm 1.2$ & $2.8 \pm 1.0$ \\
E15 & 17 & $12.3 \pm 4.9$ & $4.1 \pm 1.9$ & 70 & $3.3 \pm 2.3$ & $4.2 \pm 3.7$ \\
Optic tract & & & & & & \\
E14 & 15 & $9.2 \pm 3.2$ & $2.4 \pm 0.8$ & 40 & $2.5 \pm 1.8$ & $3.5 \pm 2.3$ \\
E15 & 7 & $9.1 \pm 2.4$ & $2.3 \pm 1.4$ & 42 & $2.0 \pm 0.0$ & $2.5 \pm 1.0$ \\
E16 & 20 & $7.9 \pm 1.6$ & $1.9 \pm 0.6$ & 65 & $1.2 \pm 0.6$ & $2.7 \pm 1.1$
\end{tabular}

Dimensions of growth cones of the optic nerve, chiasm, and tract at different ages during the major period of outgrowth in each region. Tract growth cones included only those found midway between chiasm and target entry zones. Average measurements are given \pm SE. The average number and length of filopodia (fourth and fifth columns) were calculated for only those growth cones having filopodia (third column). 


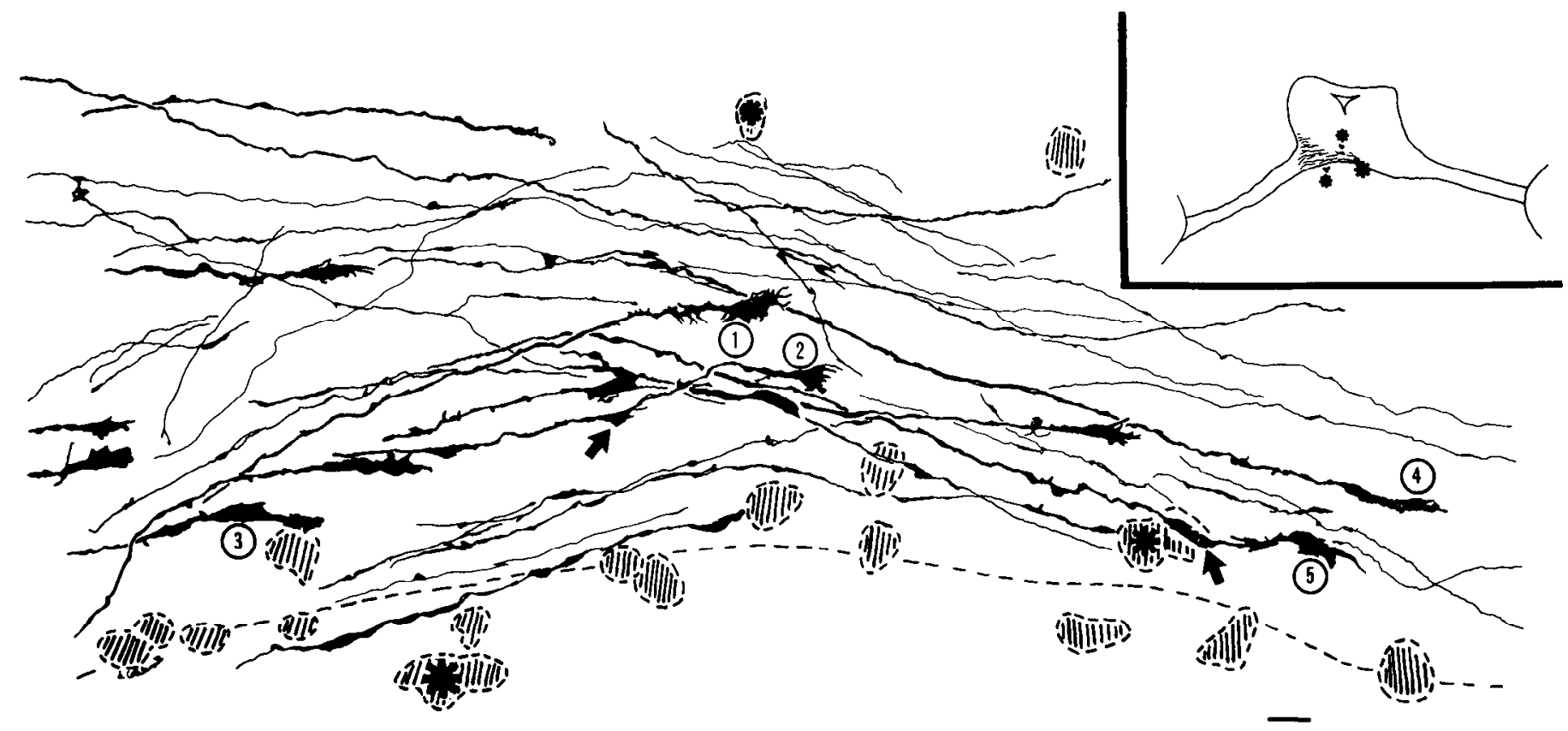

Figure 4. Camera lucida drawing of HRP-labeled retinal axons and growth cones at E14, in a single $50 \mu \mathrm{m}$ osmicated vibratome section through the optic chiasm and diencephalon (inset), showing many of the labeled fibers in actual relationship to one another. Note that axons do not run parallel to one another but intertwine. The majority of fibers with growth cones run close to the pial surface (dotted lines). Growth cones 1 and 2 have filopodia and complex shapes, while growth cones 3 and 4 lack filopodia and resemble growth cones in the optic nerve (Fig. 2). Growth cone 5 has an intermediate shape. En passant swellings or expansions proximal to the growth cone occur on many fibers (arrows on axons 2 and 5). Shaded structures are blood cells and vessels, marked with asterisks to refer to those in inset. Scale bar, $10 \mu \mathrm{m}$.

were seen within the zona incerta and formed branched arbors (Fig. 6a). Transient projections to such nonvisual structures have been previously described in neonatal hamsters (Frost, 1984).

\section{Cell-cell relationships of growth cones}

Several growth cones were analyzed at the ultrastructural level, in a first attempt to characterize cell-cell relationships during outgrowth along differen. parts of the pathway. All of the 10 growth cones analyzed in the optic nerve were either growing completely apposed to immature glial (neuroepithelial) cells or contacted them somewhere along their length.

One long but simple growth cone, located on the lateral portion of the optic nerve close to the retina, was positioned adjacent to neuroepithelial cells that formed the border of the nerve and closely followed their contours (Fig. 7a). An adjacent neuroepithelial cell made an intimate contact with the growth cone by inserting a small protrusion of cytoplasm into an expanded portion of the growth cone (Fig. $7 b$ ). This insertion could be followed for some distance in serial sections and later was seen to be completely engulfed by the growth cone (Fig. 7e). The tip of the same labeled growth cone also ran between a glial cell and another unlabeled growth cone profile (Fig. 7, $c, d$, insert). A small tongue of the HRP-filled growth cone insinuated into the unlabeled growth cone (Fig. $7 \mathrm{c}$ ) and after few sections was enclosed in the cytoplasm of the unlabeled profile (Fig. $7 d$ ). Thus, the same growth cone was involved in glial-growth cone insertions, as well as growth cone-growth cone insertions.

Another sampled fiber (Fig. 8), tipped by a lamellopodial growth cone, at first ran in the central portion of the nerve and then abruptly turned toward the lateral side. The tip of the growth cone was positioned between other neurites, close to a glial cell (Fig. 8c). The major enlargement of the labeled growth cone grew apposed to glial cells on one aspect and contacted other unlabeled neuritic elements on the other aspect. Sections through the concave expansion show that it was enveloping other neuritic profiles (Fig. $8 a$ ). This sort of section shows that growth cones enfold other axons that run in a fasicle. The lamellopodial expansions of the central core of the growth cone could represent the amorphous profiles often observed in cross sections of normally fixed optic nerve (Fig. $8 b$ ). These expansions usually lacked organclles and wcre positioned in between neuroepithelial cells and bundles of neurites. From simply observing such unlabeled material, it was formerly difficult to identify these profiles as neuronal or glial (Williams et al., 1986; Carpenter and Guillery, personal communication).

In central portions of the nerve, growth cones contacted glial cells at several points along their length but were not growing completely apposed to them (data not shown). In general, it appeared that each labeled growth cone profile in the optic nerve contacted only few other neighboring cells.

In the chiasm, fibers regularly criss-cross and intertwine with one another and weave among radial glia. Growth cones were positioned among these crossings, and in thin sections it was apparent that each growth cone simultaneously touched many other profiles, either neurites, other growth cones, or glial processes (Fig. 9). One growth cone with a highly convoluted surface apposed a glial cell profile and several other neurites, some of which were oriented perpendicular to the growth cone (Fig. 9a, arrows). Several profiles also contacted the base of a second chiasm growth cone (Fig. 9b). At the light level, convoluted expansions were observed, while in the thin sections through this region, the labeled portions appeared in several pieces (Fig. $9 b$ ), confirming the existence of the surface convolutions. One 


\section{$\begin{array}{llll}E 14 & E 15 & E 16 & E 17\end{array}$}

a.

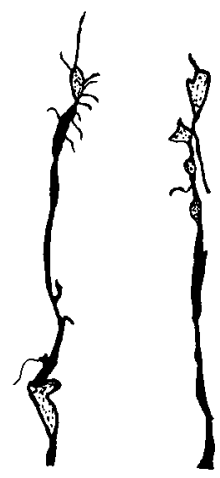

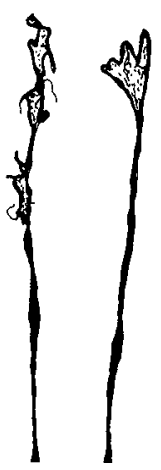
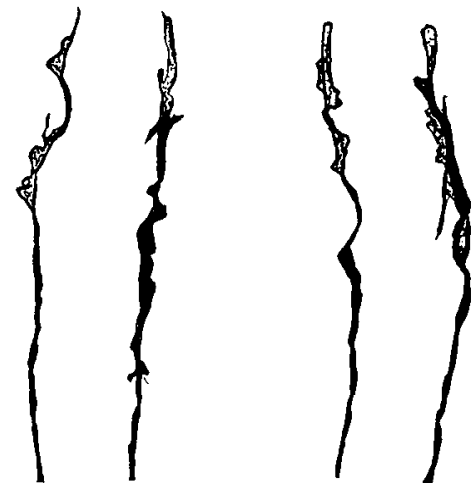

b.
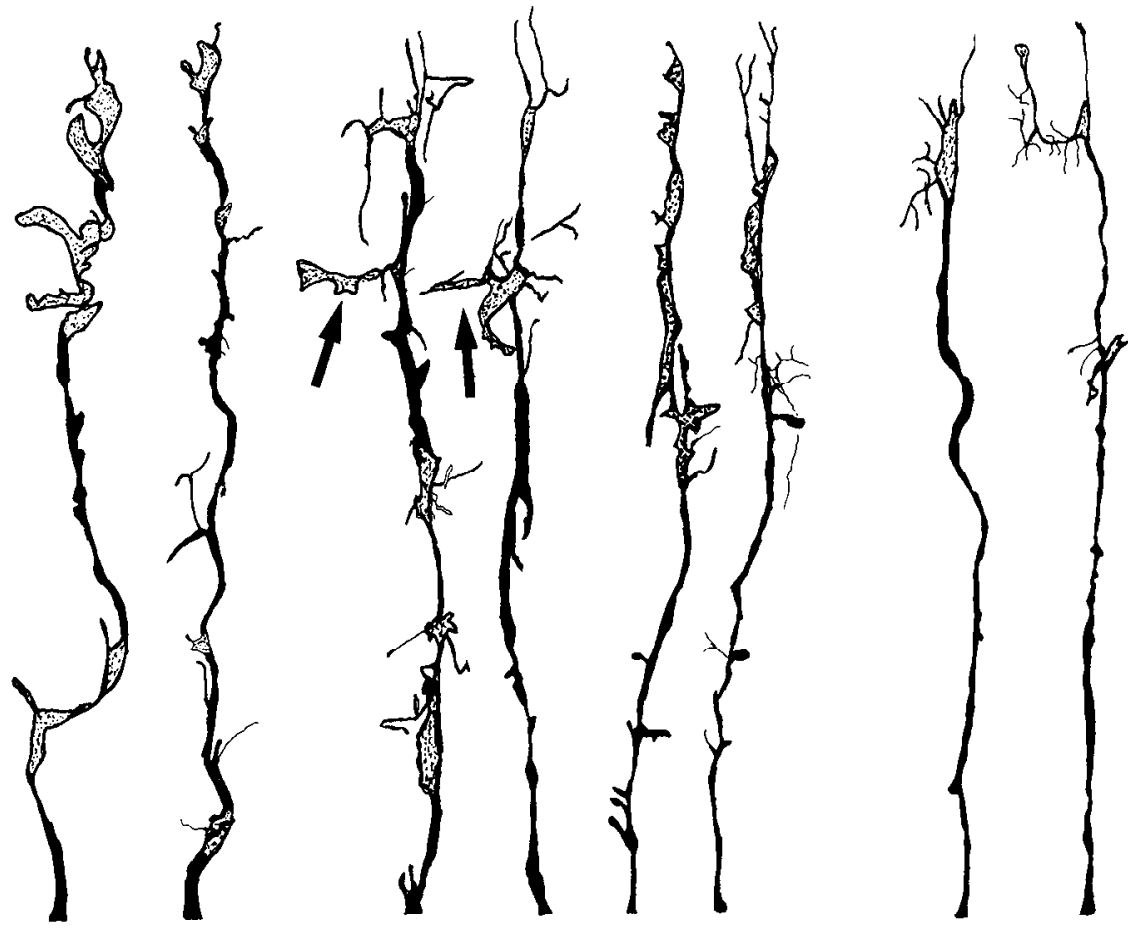

\section{OPTIC TRACT}

Figure 5. Camera lucida drawings of retinal axons in the tract at various ages. Fibers in $a$ are localized on the outer surface of the tract. The growth cones of these axons are shorter, more slender versions of optic nerve growth cones. Fibers in $b$ are positioned in the inner part of the tract, adjacent to the lateral geniculate nucleus ( $\mathrm{lg}$, inset). Growth cone-like expansions (arrows) arise from the main shaft and project toward the target. Filopodia are prominent on these expansions and extend in all directions. Age of the embryo did not correlate with growth cone form in either position. Scale bar, $10 \mu \mathrm{m}$.

of the filopodia on this growth cone insinuated between other neuritic profiles. Among the chiasm growth cones with filopodia that were analyzed in the EM, no specialized contacts between filopodia and other cells were noted.

\section{Discussion}

Shape changes of retinal axon growth cones are position-specific

The major finding of this analysis, summarized in Figure 10, is that the growth cones of retinal ganglion cell axons have different shapes according to their position along the visual pathway. The shapes range from long contoured forms that generally lack filopodia in the optic nerve and tract, to shortened spread forms with filopodia in the optic chiasm, and filopodial expansions at the border of targets. Upon entering targets, including inappropriatc oncs, retinal axon endings branch into arbors, but each branch is tipped by minute growing tips rather than the enlarged forms seen during outgrowth.

These data demonstrate that there are remarkable similarities in growth cone morphologies among a wide variety of invertebrates and vertebrates, in regions where they follow a common pathway, in positions where they diverge, and in loci where they interact with target cells (Tosney and Landmesser, 1985a; Caudy and Bentley, 1986a). In the chick PNS, motor neuron growth 
a

E 16

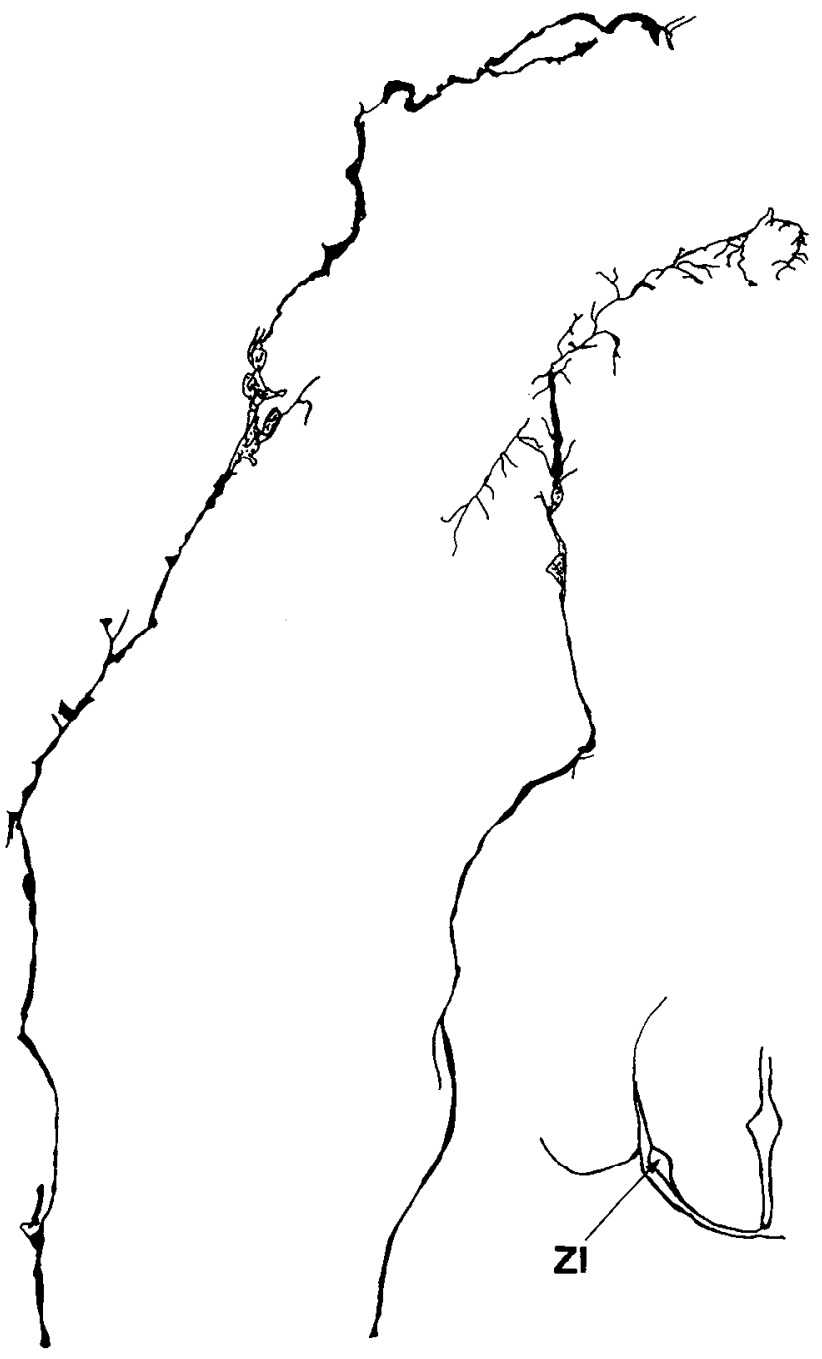

b

E 17

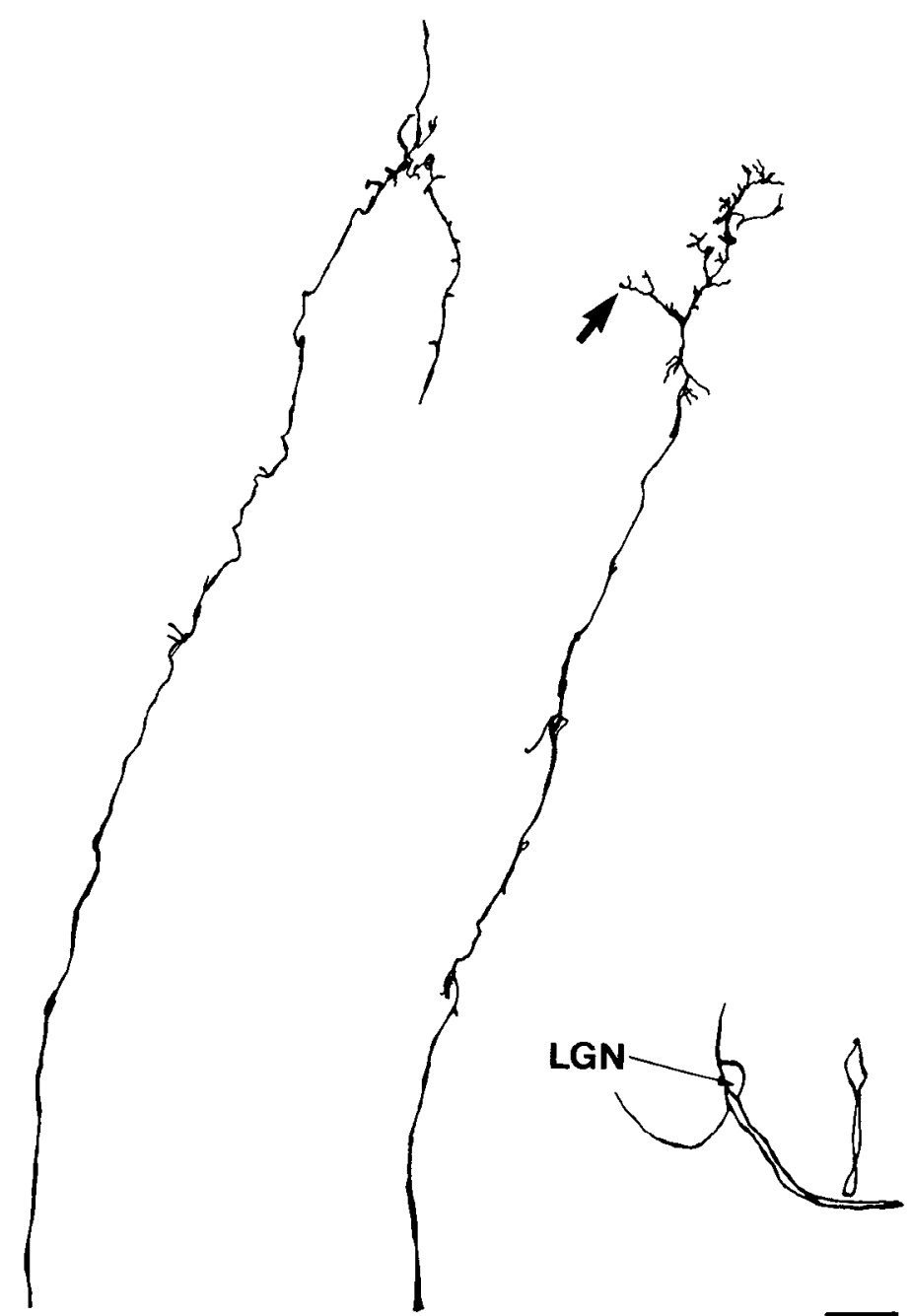

Figure 6. Camera lucida drawings of retinal axon arbors within target regions. $a$, At E16, fibers within the optic tract branch into a nonvisual target, the zone incerta $(Z I)$, which is thought to be a transient projection of immature retinal axons. $b$, At E17, labeled fibers arborize within the ventral lateral geniculate nucleus $(L G N)$. Rather than ending with a single large growth cone, these axons have a finely divided branched terminal arbor, tipped with minute swellings (arrow). Note that the immature branching patterns and growing tips of retinal arbors are similar both within inappropriate and appropriate target regions. Scale bar, $10 \mu \mathrm{m}$.

cones are larger and more elaborate in "decision regions," such as the plexi or where muscle nerves diverge from the main nerve trunk (Tosney and Landmesser, 1985a). In grasshopper neurons, growth cones are simple within connectives, but when growth cones interact specifically with other identified neurons, their morphology becomes complex, with extremely long filopodia (Raper et al., 1983; Caudy and Bentley, 1986b).

The forms observed in this study correspond to the few depictions of growth cones in vertebrate nervous systems in situ (e.g., Ramon y Cajal, 1960; Thanos and Bonhoeffer, 1983; Nordlander, 1985; Tosney and Landmesser, 1985a; Whitehead and Morest, 1985; Kuwada, 1986; Myers et al., 1986), regardless of the technique used (Golgi impregnation, dye injection, and electron-microscopic methods). Retinal axon growth cones in chick retina and monkey optic nerve closely resemble the elon- gated lamellopodial growth cones in mouse optic nerve (Jackowski and Lieberman, 1979; Williams and Rakic, 1985). Short filopodia were revealed on some chick retina and mouse optic nerve growth cones by the Golgi and HRP labeling techniques but were not detected on monkey optic nerve growth cones in serial thin sections. Growth cones on amphibian sensory axons visualized with scanning electron microscopy display the flattened filopodial shapes commonly seen in vitro in certain cellular environments such as myotomes (Roberts and Taylor, 1983). In agreement with the present study, growth cone form changes with the cellular surround and become more simple and blunt on skin basal lamina. In regenerating frog optic nerve, growth cones display the range of forms seen in mouse optic nerve with HRP labeling (Scalia and Matsumoto, 1985). Position-specific trends in morphology were not obvious, but regenerating axons 

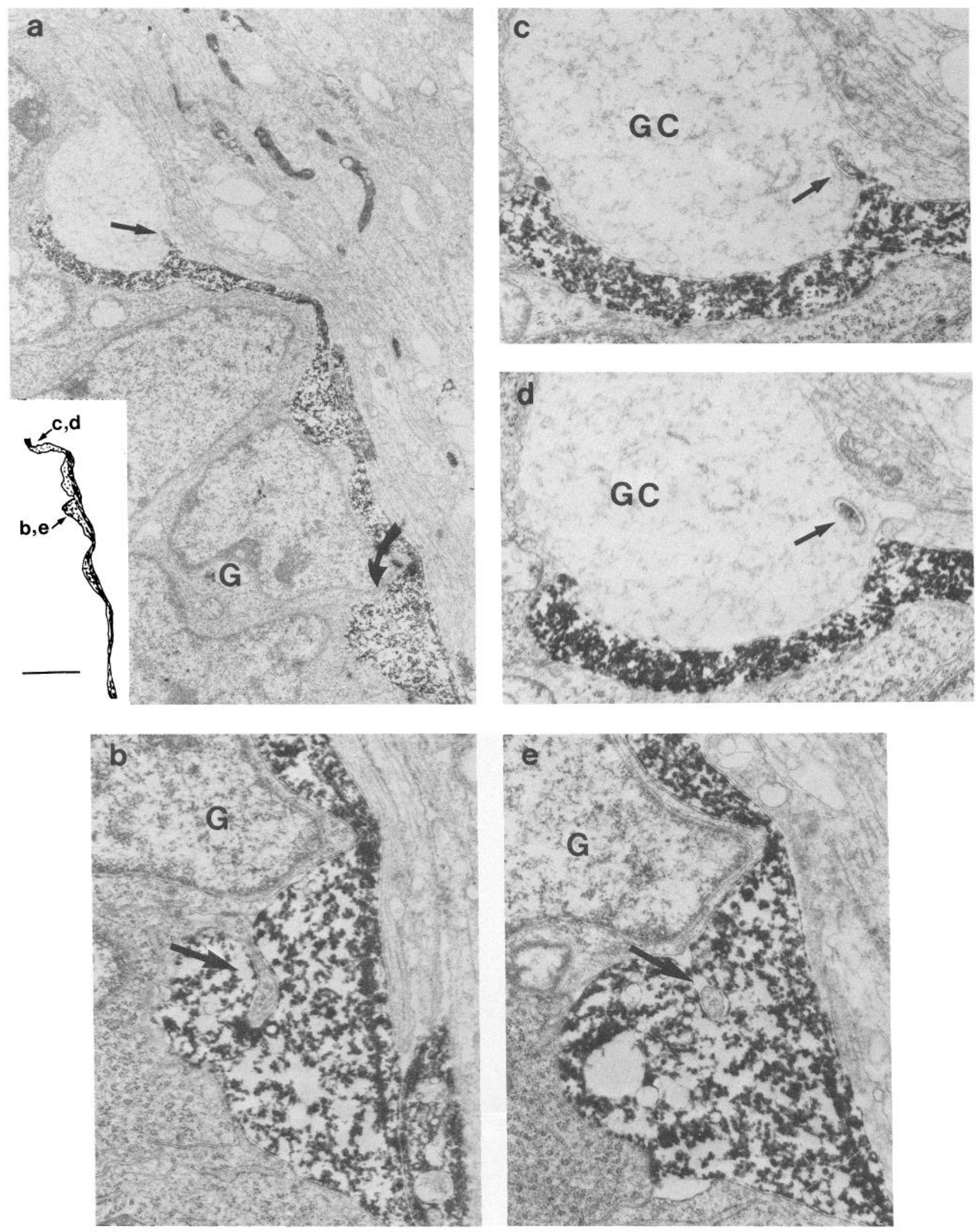

Figure 7. Electron micrographs of an HRP-labeled growth cone in the optic nerve at E13, demonstrating the invaginating contacts made by growth cones. Inset, Drawing of the light-microscopic image of this growth cone. $a$, Growth cone follows the contours of immature glial cells $(G)$. $b$ and $e$, Glial protrusion $(G)$ inserts into the labeled growth cone (arrows). $c$, Toward the tip $(c, d$, inset), the growth cone inserts a small protrusion into the invaginated surface of a nearby growth cone $(G C)$. $d$, As seen a few sections away, the expansion is completely enclosed by the membrane of the unlabeled growth cone (arrow, GC). Scale bar (inset), $10 \mu \mathrm{m} .(a) \times 7500 ;(b-e) \times 20,000$. 

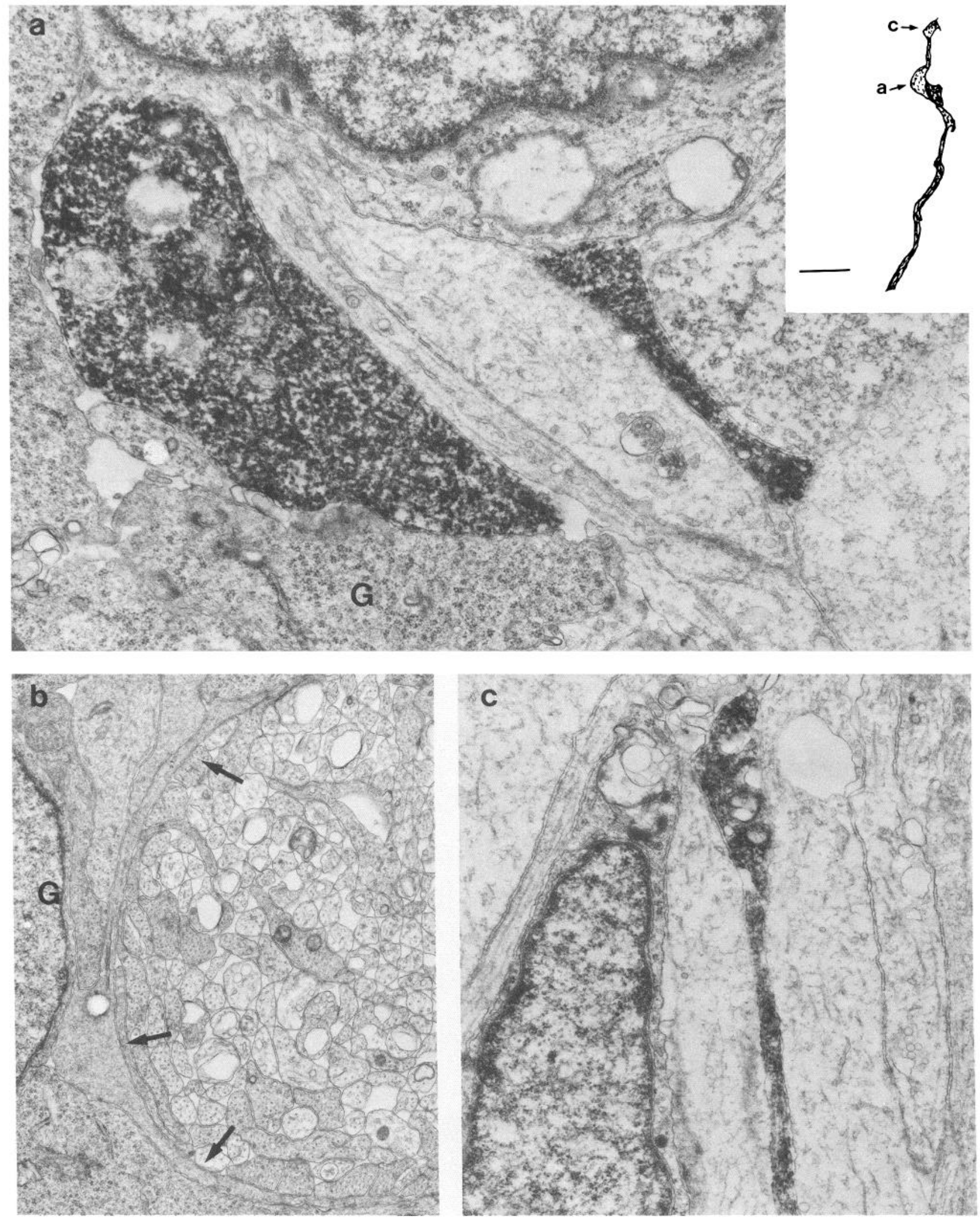

Figure 8. Electron micrographs of an HRP-labeled optic nerve growth cone at E13, showing that the convex and concave expansions seen at the light level (Fig. 2) wrap around other neurites. Inset, Drawing of the light-microscopic image of this growth cone. $a$, This expansion of the growth cone $(a$, inset $)$ enfolds 2 other neurites and apposes glial cells $(G) . b$, Cross section through an uninjected optic nerve at E13. Amorphous profiles (arrows) surround bundles of axons and appose glial cells $(G)$. This sort of profile may represent the growth cone expansions that wrap around bundles of neurites shown in $a$ in longitudinal section. $c$, The tip of the HRP-labeled growth cone is interposed among other neurites and contains large vesicles of the sort commonly seen in aldehyde-fixed growth cones. Scale bar (inset), $10 \mu \mathrm{m} .(a, c) \times 20,000 ;(b) \times 12,500$. 

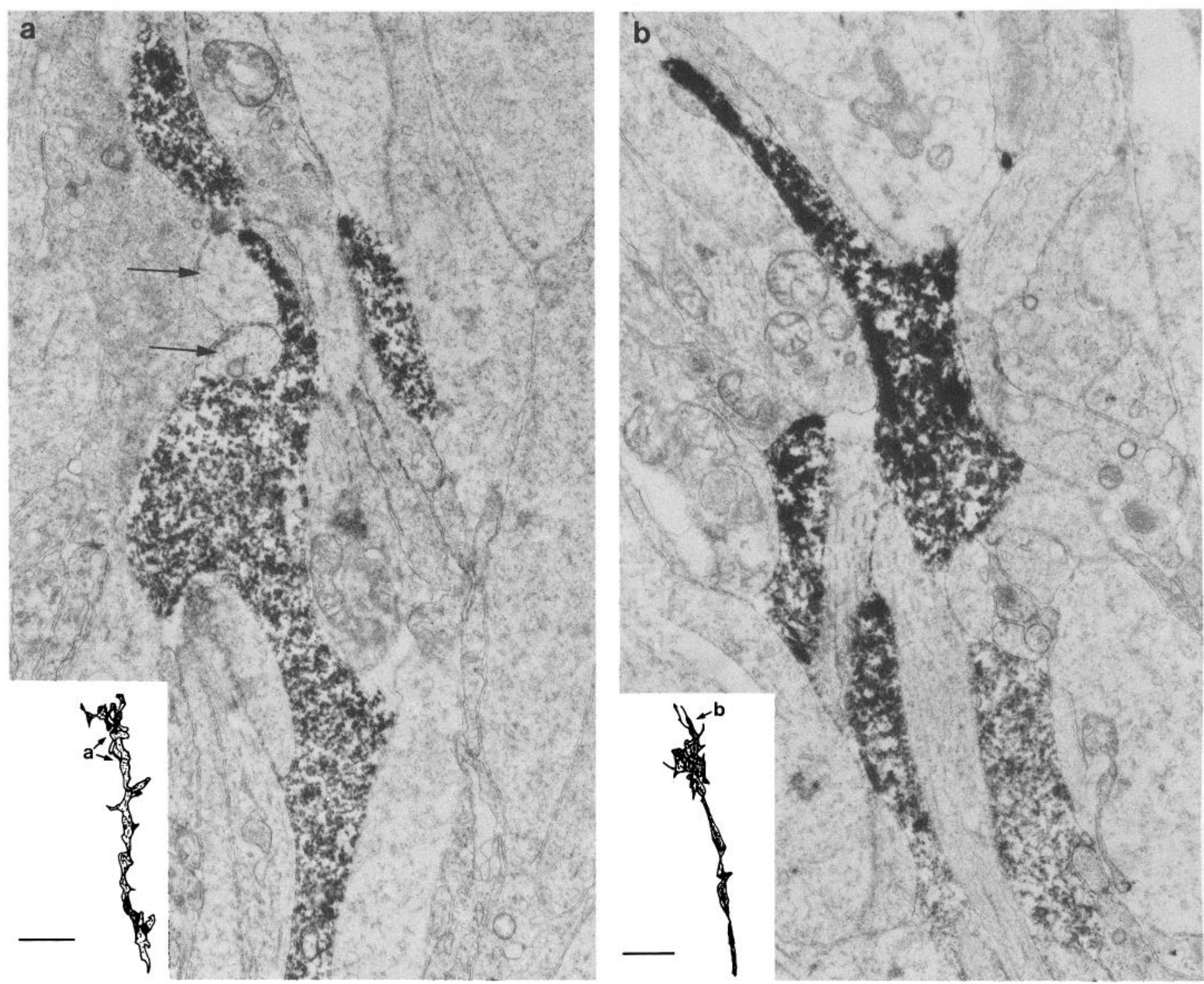

Figure 9. Electron micrographs of HRP-labeled growth cones in the chiasm at E13. Insets show drawings of the light-microscopic images of these growth cones. $a$, Labeled portion of this highly convoluted growth cone contacts many profiles, some running perpendicular to others (arrows). These profiles are most likely other growth cones, neurites, and glia. $b$, One filopodia of this growth cone is positioned between other neurites, but no specialized contact was seen. Several nonlabeled profiles criss-cross and indent the labeled body of the growth cone, causing it to appear in several portions in this section, and possibly accounting for its complex shape. Scale bar (insets), $10 \mu \mathrm{m} .(a, b) \times 20,000$.

may have different properties and responses (Grant and Tseng, 1986).

Other studies on growth cones in situ support our observations that, just outside of targets, growth cones have the elaborate form of growth cones found in decision regions (Harris et al., 1985; Mason, 1985; Nordlander, 1985; Young and Rubel, 1986), but within targets, immature axon arbors have small tapered tips or miniature growth cones (Mason, 1982, 1985; Reh and Constantine-Paton, 1985; Sakaguchi and Murphey, 1985; Sachs et al., 1986; Sretavan and Shatz, 1986). A surprising observation of the present study is that growth cones become smaller in both appropriate and inappropriate targets.

\section{Factors responsible for changes in growth cone shape and behavior}

While the correlation between shape and behavior is consistent even across phylogenetic lines, the factors controlling growth cone movement and morphogenesis as axons extend through different environments are not understood. One popular concept is that growth cones have differential affinities to molecular cues in the local environment and subsequently change form as they register these cues. An example of such cues are gradients of adhesive molecules (Nardi, 1983; Berlot and Goodman, 1984). The notion that growth cone form reflects the degree of adhesivity was derived from in vitro studies (Letourneau, 1979, 1982). On highly adhesive substrates, growth cones move rapidly and have a characteristic spread form with lamellopodia and filopodia, whereas on less adhesive substrates, growth cones move slowly and have contracted forms.

This model of hierarchical affinities has been recently applied to growth cone behavior in developing grasshopper limbs (Caudy and Bentley, 1986a). Filopodia and lamellopodia are most numerous along segmental boundaries where growth cones reorient during navigation. The data at present do not distinguish 


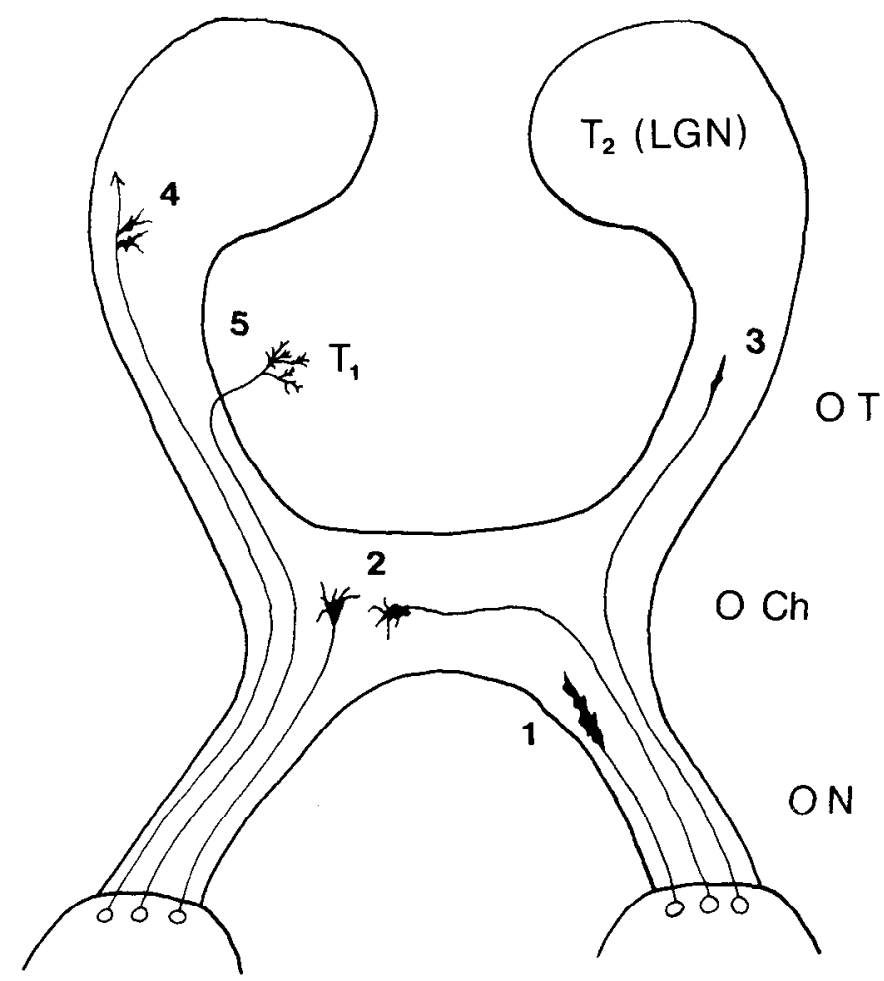

Figure 10. Schematic representation of the changes in growth cone morphology at different positions along the visual pathway. 1 , In the optic nerve $(O N)$, growth cones are long and indented and lack filopodia. 2 , Within the optic chiasm $(O C h)$, growth cones are shortened and have multiple filopodia. 3 , In the optic tract $(O T)$, growth cones resemble optic nerve growth cones but are not as broad (1). 4, At the borders of target regions, such as the lateral geniculate nucleus $\left(T_{2}, L G N\right)$, filopodial growth cones arise from lengths of axon, and project toward the target. 5 , Within target regions, finely branched arbors have simple small tips. This arbor is depicted in the zona incerta $\left(T_{i}\right)$, which may be a transient target of retinal axons.

whether affinity to segmental borders is derived from adhesion molecules on cell membranes or in the extracellular matrix, or from other more soluble factors that influence growth cone extension (Gunderson and Barrett, 1980; Haydon et al., 1984; Connolly et al., 1985). Nonetheless, while the role of filopodia in neurite advance has been disputed (Marsh and Letourneau, 1984; Bray and Chapman, 1985), these observations support the idea that filopodia mediate cell-cell interactions (Bastiani and Goodman, 1984).

The transformation of retinal axons observed in the present study from predominantly nonfilopodial to more complex filopodial forms in regions where directionality changes is consistent with this hypothesis. However, the precise morphological transformations that occur in decision regions or turning points are not strictly the same in all animals. Motor neuron growth cones in decision regions in the chick PNS have more prominent lamellopodia than at nondecision regions, and filopodia can be common on growth cones in both areas. The morphogenetic changes might reflect intrinsic properties of growth cones of different types of neuron (Haydon et al., 1985; Tosney and Landmesser, 1985a; Nordlander, 1985).

There are at least 2 other factors that should be considered for any model of differential affinity and subsequent induction of growth cone morphogenesis: rate of growth cone extension and age of the neuron. Argiro et al. (1984) correlated rate of neurite outgrowth with growth cone form in a single neuron population grown on a constant substrate. Growth cones that moved most rapidly had only lamellopodia, growth cones that extended at moderate rates or paused had prominent filopodia, while the slowest moving growth cones were slender and tapered, with short filopodia. By extrapolation, the growth cones observed in the present study would extend fastest in the optic nerve, slow down in the chiasm, and move very slowly indeed in targets. The resemblance of some growth cones in the chiasm to the lamellopodial growth cones in the optic nerve suggests that growth cones move at different rates, or in a saltatory manner. The latter behavior has been observed in mouse cerebellar axon and PC12 cell growth cones in vitro in real time (Aletta et al., 1986; Mason and Hatten, unpublished observations).

In the present study, age-related differences in growth cone shape were minimal, in agreement with observations on motor neuron growth cones in chick peripheral nerve (Tosney and Landmesser, 1985a). In other systems, the repertoire of growth cone form is related both to chronological age of the neuron (Argiro et al., 1984) and to order of outgrowth. In Xenopus spinal cord, growth cones both in younger animals and in the leading edge of outgrowth are more complex than growth cones in older animals or in the follower population (Nordlander, 1985). The lead neurons in Daphnia eye during early development in the first part of the pathway have expanded specializations at their tips, whereas the followers do not (Lopresti et al., 1973). In cat optic nerve, however, the earliest growth cones in the optic nerve are simpler than later-growing ones (Williams et al., 1986), as we observed in the present study.

\section{Position and cellular relationships of growth cones in pathways}

Retinal axon growth cones were differentially located in each portion of the visual pathway. In the optic nerve, growth cones are positioned at the edges as well as inner portions of the nerve, agreeing with the findings of Williams et al. (1986) in cat optic nerve. In contrast, growth cones grow on the pial aspect of the chiasm and the optic tract, as they do in the ferret optic tract (Walsh and Guillery, 1985). In the latter system, new axons are added near the pial surface, displacing older axons toward the deeper parts of the tract as development proceeds. Our observations also show that growth cones projecting toward thalamic targets arise from axons positioned away from the pia. This suggests that there may be a lag time between outgrowth to, and entry to, targets, as postulated by Schneider et al. (1985) for growing retinocollicular axons in the hamster.

The correlated light-microscopic and ultrastructural analysis of labeled growth cones has shown that the curved lamellopodial expansions on optic nerve growth cones envelop bundles of other neurites. In this respect, fasiculating growth cones in vitro closely resemble HRP-labeled retinal growth cones in the optic nerve. When extending on the culture substratum, growth cones have spread filopodial forms, but upon meeting other neurites, quickly elongate and embrace the other neurites with lamellopodia (Letourneau, unpublished observations).

The present observations demonstrate that some, but not all, growing axons in the optic nerve contact glia, but the data do not necessarily implicate an obligatory relationship between neurons and glia (Easter et al., 1984; Silver, 1984). The growth cone-cell appositions are, however, quite intimate, in the form of protrusions of the growth cone into the invaginated membrane of primitive glia, as well as into other growth cones. The 
earliest motor neuron growth cones in chick make similar invaginating contacts into mesenchyme cells in the path of outgrowth to the hindlimb (Tosney and Landmesser, 1985b). In grasshopper embryos, filopodia of particular growth cones insert into guidepost cells (Bastiani and Goodman, 1984), and coated pits and coated vesicles form near the filopodial insertion sites. In the grasshopper system, the invaginating contacts and associated endocytosis are thought to provide information for subsequent turning of the growth cone. Endocytotic events have also been observed in ependymal cells and in axons of the newt spinal cord during regeneration (Nordlander and Singer, 1978) and at the base of filopodia in growth cones within developing chick optic tectum (Cheng and Reese, 1985). It was surprising to find insertions between growth cones and other cells within the main portion of the optic nerve, where, in contrast to the optic nerve head or the chiasm, turning or fiber resorting presumably docs not occur (Torrealba et al., 1982; Walsh et al., 1985).

In summary, growth cones are long and lamellopodial when axons traverse straight pathways, more elaborate, especially with reference to filopodia, within the optic chiasm and at the border of target regions, and small and simple on branched arbors in targets. The demonstration of orderly changes in growth cone morphology in different positions of developing pathways should provide a basis for investigating the interactions that operate during axon outgrowth and synaptogenesis in situ. Testing the factors responsible for growth cone shape changes can, in turn, indicate whether morphology can be used as a predictor of cellcell and molecular interactions.

\section{References}

Adams, J. C. (1981) Heavy metal intensification of DAB-based HRP reaction product. J. Histochem. Cytochem. 29: 775.

Aletta, J. M., L. A. Greene, and J. C. Edmondson (1986) Cytological features observed during NGF-dependent neurite elongation and growth cone motility in PC12 cells. Soc. Neurosci. Abstr. 12: 368 .

Argiro, V., M. B. Bunge, and M. I. Johnson (1984) Correlation between growth cone form and movement and their dependence on neuronal age. J. Neurosci. 4: 3051-3062.

Bastiani, M. J., and C. S. Goodman (1984) Neuronal growth cones: Specific interactions mediated by filopodial insertion and induction of coated vesicles. Proc. Natl. Acad. Sci. USA 81: 1849-1853.

Berlot, J., and C. S. Goodman (1984) Guidance of peripheral pioneer neurons in the grasshopper: Adhesive hierarchy of epithelial and neuronal surfaces. Science 223: 493-496.

Bray, D., and M. Bunge (1973) The growth cone in neurite extension. In Locomotion of Tissue Cells, W. Porter and D. W. Fitzsimmons, eds., Ciba Foundation Symp. 14: 195-209.

Bray, D., and K. Chapman (1985) Analysis of microspike movements on the neuronal growth cone. J. Neurosci. 5: 3204-3213.

Caudy, M., and D. Bentley (1986a) Pioneer growth cone morphologies reveal proximal increases in substrate affinity within leg segments of grasshopper embryos. J. Neurosci. 6: 364-379.

Caudy, M., and D. Bentley (1986b) Pioneer growth cone steering along a series of neuronal and non-neuronal cues of different affinities. J. Neurosci. 6: 1781-1795.

Cheng, T. P. O., and T. S. Reese (1985) Polarized compartmentalization of organelles in growth cones from developing optic tectum. J. Cell Biol. 101: 1473-1478.

Connolly, J. L., P. J. Seeley, and L. A. Greene (1985) Regulation of growth cone morphology by nerve growth factor: A comparative study by scanning electron microscopy. J. Neurosci. Res. 13: 183-198.

Easter, S. S., B. Bratton, and S. S. Scherer (1984) Growth-related order of the retinal fiber layer in goldfish. J. Neurosci. 4: 2173-2190.

Frost, D. O. (1984) Axon growth and target selection during development: Retinal projections to the ventro-basal complex and other "non-visual" structures in neonatal syrian hamster. J. Comp. Neurol. 230: 576-592.
Grant, P., and Y. Tseng (1986) Embryonic and regenerating Xenopus retinal fibers are intrinsically different. Dev. Biol. 114: 475-491.

Gundersen, R. W., and Barrett J. N. (1980) Characterization of the turning response of dorsal root neurites toward nerve growth factor. J. Cell Biol. 87: 546-554.

Harris, W. A., C. E. Holt, T. A. Smith, and N. Gallenson (1985) Growth cones of developing retinal cells in vivo, on culture surfaces, and in collagen matrices. J. Neurosci. Res. 13: 101-122.

Haydon, P. G., D. P. McCobb, and S. B. Kater (1984) Serotonin selectively inhibits growth cone motility and synaptogenesis of specific identified neurons. Science 226: 561-564.

Haydon, P. G., C. S. Cohan, D. P. McCobb, H. R. Miller, and S. B. Kater (1985) Neuron-specific growth cone properties as seen in identified neurons of Heliosoma. J. Neurosci. Res. 13: 135-147.

Jackowski, A., and A. R. Lieberman (1979) Axonal growth cones of chick retinal ganglion cells. J. Anat. 129: 866-869.

Johnston, R. N., and N. K. Wessells (1980) Regulation of the elongating nerve fiber. Current Topics Dev. Biol. 16: 165-206.

Keshishian, H. (1980) The origin and morphogenesis of pioneer neurons in the grasshopper metathoracic leg. Dev. Biol. 80: 388-397.

Kuwada, J. (1986) Cell recognition by neuronal growth cones in a simple vertebrate embryo. Science 233: 740-746.

Landis, S. (1983) Neuronal growth cones. Annu. Rev. Physiol. 45: 567-580.

Letourneau, P. C. (1979) Cell-substratum adhesion of neurite growth cones, and its role in neurite elongation. Exp. Cell Res. 124: 127138.

Letourneau, P. C. (1982) Nerve fiber growth and its regulation by extrinsic factors. In Neuronal Development, N. C. Spitzer, ed., pp. 213-254, Plenum, New York.

Lopresti, V., F. R. Macagno, and C. Levinthal (1973) Structure and development of neuronal connections in isogenic organisms: Cellular interactions in the development of the optic lamina of Daphnia. Proc. Natl. Acad. Sci. USA 70: 433-437.

Marsh, L., and P. C. Letourneau (1984) Growth of neurites without filopodial or lamellipodial activity in the presence of cytochalasin B. J. Cell Biol. 99: 2041-2047.

Mason, C. A. (1982) Development of terminal arbors of retinogeniculate axons in the kitten. I. Light microscopical observations. Neuroscience 7: 541-560.

Mason, C. A. (1985) Growing tips of embryonic cerebellar axons in vivo. J. Neurosci. Res. 13: 55-73.

Mason, C. A., and E. Gregory (1984) Postnatal maturation of cerebellar mossy and climbing fibers: Transient expression of dual features on single axons. J. Neurosci. 4: 1715-1735.

Myers, P. Z., J. S. Eisen, and M. Westerfield (1986) Development and axonal outgrowth of identified motoneurons in the zebrafish. J. Neurosci. 6: $2278-2289$.

Nardi, J. B. (1983) Neuronal pathfinding in developing wings of the moth Manduca sexta. Dev. Biol. 95: 163-174.

Nordlander, R. H. (1985) Wholemount views of axonal growth cones in the developing spinal cord of Xenopus. Soc. Neurosci. Abstr. 11: 586.

Nordlander, R. H., and M. Singer (1978) The role of ependyma in regeneration of the spinal cord in urodele amphibian tail. J. Comp. Neurol. 180: 349-374.

Ramon y Cajal, S. (1960) Studies on Vertebrate Neurogenesis, L. Guth, trans., Thomas, Springfield, IL.

Raper, J. A., M. J. Bastiani, and C. S. Goodman (1983) Guidance of growth cones: Selective fasiculation in the grasshopper embryo. Cold Spring Harbor Symp. Quant. Biol. 48: 587-598.

Rees, R. P., M. B. Bunge, and R. P. Bunge (1976) Morphological changes in neurite growth cone and target neuron during synaptic function development in culture. J. Cell Biol. 66: 240-263.

Reh, T. A., and M. Constantine-Paton (1985) Growth cone-target interactions in the frog retinotectal pathway. J. Neurosci. Res. 15: $89-100$.

Roberts, A., and J. S. H. Taylor (1983) A study of the growth cones of developing embryonic sensory neurites. J. Embryol. Exp. Morphol. 75: 31-47.

Sachs, G. M., M. Jacobson, and V.S. Caviness (1986) Postnatal changes in arborization patterns of murine retinocollicular axons. J. Comp. Neurol. 146: 395-408.

Sakaguchi, D. S., and R. K. Murphey (1985) Map formation in the developing Xenopus retinotectal system: An examination of ganglion 
cell terminal arborizations. J. Neurosci. 5: 3228-3245.

Scalia, F., and D. E. Matsumoto (1985) The morphology of growth cones of regenerating optic nerve axons. J. Comp. Neurol. 231: 323338 .

Schneider, G. E., S. Jhaveri, M. A. Edwards, and K. So (1985) Regeneration, re-routing, and redistribution of axons after early lesions: Changes with age and functional impact. In Recent Achievements in Restorative Neurology 1: Upper Motor Neuron Functions and Dysfunctions, I. Eccles and M. R. Dimitrijevic, eds., pp. 291-310, Karger, Basel.

Silver, J. (1984) Studies on the factors that govern directionality of axonal growth in the embryonic optic nerve and at the chiasm of mice. J. Comp. Neurol. 223: 238-245.

Sretavan, D. W., and C. J. Shatz (1986) Prenatal development of retinal ganglion cell axons: Segregation into eye-specific layers within the cat's lateral geniculate nucleus. J. Neurosci. 6: 234-251.

Thanos, S., and F. Bonhoeffer (1983) Investigation on the development and topographic order of retinotectal axons: Anterograde and retrograde staining of axons and perikarya with rhodamine in vivo. J. Comp. Neurol. 219: 420-430.

Torrealba, F., R. W. Guillery, V. Eysel, E. H. Polley, and C. A. Mason (1982) Studies of retinal representations within the cat's optic tract. J. Comp. Neurol. 211: 377-396.
Tosney, K. W., and L. T. Landmesser (1985a) Growth cone morphology and the trajectory in the lumbosacral region of the chick embryo. J. Neurosci. 5: 2345-2358.

Tosney, K. W., and L. T. Landmesser (1985b) Development of the major pathways for neurite outgrowth in the chick hindlimb. Dev. Biol. 109: 193-214.

Walsh, C., and R. W. Guillery (1985) Age-related fiber order in the optic tract of the ferret. J. Neurosci. 5: 3061-3069.

Walsh, C., S. Price, and R. W. Guillery (1985) Glial structure in relation to fiber order in the ferret's optic stalk. Soc. Neurosci. Abstr. I1: 15.

Whitehead, M. C., and D. K. Morest (1985) The development of innervation patterns in the avian cochlea. Neuroscience 14: 255-276.

Williams, R. W., and P. Rakic (1985) Disposition of growing axons within the optic nerve of embryonic monkey. Proc. Natl. Acad. Sci. USA 82: 3906-3910.

Williams, R. W., M. J. Bastiani, B. Lia, and L. M. Chalupa (1986) Growth cones, dying axons and developmental fluctuations in the fiber population of the cat's optic nerve. J. Comp. Neurol. 246: 3269.

Young, S., and E. W. Rubel (1986) Embryogenesis of arborization pattern and topography of individual axons in N. laminaris of the chicken brain stem. J. Comp. Neurol. 254: 425-459. 